\title{
Medir Progresos en Educación en Derechos Humanos: Una Experiencia Interamericana en Marcha'
}

\author{
Diego Iturralde y Ana María Rodino² \\ Instituto Interamericano de Derechos Humanos, San José, Costa Rica
}

\begin{abstract}
Since the year 2000, the Inter-American Institute of Human Rights (IIHR) has been developing a new research methodology on human rights based on a system of progress indicators about three groups of rights: access to justice, political participation and human rights education. The approach was initially applied in 6 countries of the region, and produced the Progress Maps on Human Rights. This experience set the foundations for the annual preparation of the Inter-American Report on Human Rights Education, which IIHR distributes every December 10th, since 2002. The paper explains the oldest and more widely used approaches for research on human rights: (i) the registration of violations and (ii) the analysis of human rights situations. Then, it introduces the approach of measuring progress, its tools (progress indicators), the main methodological considerations, and the application of this approach, up to date, in 19 countries of the American continent that subscribed and/or ratified the San Salvador Protocol. Such application constitutes the first two Inter-American Reports on Human Rights Education, which are part of a series of 4 reports. El main objective of the series is to investigate the variations produced regarding the incorporation of Human Rights Education in formal and non-formal education, in the selected countries, during the period 1990-2002/03. The I Report (2002) focused on the legal developments of Human Rights Education at the national level, and the II Report (2003) examined the advanced in the curriculum and the textbooks in the elementary and high school levels of the formal education system. The conclusions and recommendations of both Reports are transcribed in the appendices.
\end{abstract}

Key words: Human Rights, Latinoamerica, Inter-American Institute of Human Rights, training, curriculum.

\section{RESUMEN}

Desde el año 2000, el Instituto Interamericano de Derechos Humanos (IIDH) viene desarrollando una nueva metodología de investigación sobre derechos humanos basada en un sistema de indicadores de progreso sobre tres conjuntos de derechos -el acceso a la justicia, la participación política y la educación en derechos humanos-, enfoque que fue aplicado inicialmente en 6 países de la región y produjo los Mapas de Progreso de Derechos Humanos. Esta experiencia sentó las bases para la preparación anual del Informe Interamericano sobre la Educación en Derechos Humanos, que el IIDH difunde cada 10 de diciembre, desde el 2002.El artículo explica los enfoques más antiguos y utilizados de investigación en derechos humanos: (i) el registro de violaciones y (ii) el análisis de situaciones de derechos humanos. Luego presenta el enfoque de 
medición de progreso; sus herramientas (los indicadores de progreso); las principales consideraciones metodológicas, y la aplicación realizada a la fecha en 19 países del continente americano que suscribieron y/o ratificaron el Protocolo de San Salvador. Tal aplicación constituye los dos primeros Informes Interamericanos de la Educación en Derechos Humanos, parte de una serie total de 4 informes. El objetivo general de la serie es investigar las variaciones producidas respecto a la incorporación de la EDH en la educación formal y no formal de los países seleccionados, en el período 1990-2002/03. El Informe I (2002) se centró en los desarrollos normativos de la EDH a nivel nacional, y el II Informe II (2003) examinó los avances en el currículum y los libros de texto en los niveles primario y secundario del sistema educativo formal. Como anexos se incorporan las conclusiones y recomendaciones de ambos Informes.

Descriptores: Derechos humanos, Latinoamérica, Instituto Interamericano de Derechos Humanos, enseñanza, curriculum.

\section{RÉSUMÉ}

Depuis l'an 2000, l'Institut Interaméricain des Droits de l'Homme (IIDH) a mis en cours le développement d'une nouvelle méthodologie d'investigation sur les droits de l'homme. Il s'agit $\mathrm{d}^{\prime}$ un système $\mathrm{d}$ 'indicateurs de progrès relatifs à trois différentes branches du droit - l'accès a la justice, la participation politique et l'éducation des droits de l'homme. Par le biais de cette nouvelle approche, initialement appliquée dans 6 pays de la région, des Cartes de Progrès du secteur des Droits de l'Homme furent élaborées. Cette nouvelle procédure fut à la base de la création du Rapport Interaméricain sur l'Education des Droits de l'Homme, un rapport annuel que l'IIDH publie tous les 10 décembre, depuis 2002. L'article expose les techniques d'investigation les plus communes du secteur des droits de l'homme : (i) l'enregistrement des violations et (ii) l'analyse de la situation des droits de l'homme. D'autre part, l'article présente les différents outils de mesure du progrès; les principales considérations méthodologiques et l'application, faite jusqu'à ce jour dans 19 pays du continent américain, qui ont signé et/ou ratifié le Protocole de San Salvador. Jusqu' à présent les 2 premiers rapports de la série de 4 rapports développés par l' IIDH furent appliqués. Le principal objectif de cette série de rapports est d'identifier les variations dans l'application du programme de l'EDH dans le système éducatif formel et non formel des pays sélectionnés, de 1990-2002/03. Le premier rapport (2002) focalise sur les développements normatifs de l'EDH à niveau national, alors que le second (2003) étudie les améliorations dans le curriculum et les livres de textes du primaire et du secondaire.

Mots-cléfs: Droits Humains, Latinoamerica, Institut Interaméricain des Droits de l'Homme, enseñanza, enseignement, curriculum.

\section{Enfoques de Investigación e Informes sobre Derechos Humanos}

\section{Introducción} PARTIR Del año 20oo, el Instituto Interamericano de Derechos Humanos (IIDH)
basada en un sistema de indicadores de progreso sobre tres conjuntos de derechos - el
acceso a la justicia, la participación política y la educación en derechos humanos -,
enfoque que fue aplicado inicialmente (2001-2002) en 6 países de la región ${ }^{3}$. Esta expe-
riencia dio origen a la preparación anual del Informe Interamericano sobre la Educación en
Derechos Humanos, que el IIDH presenta cada 10 de diciembre, desde el $2002^{4}$.
Esta metodología de investigación supone la adopción de un enfoque de trabajo
para la comparación en el tiempo del cumplimiento de los compromisos de los estados 
en materia de derechos humanos, y pretende ser complementaria a otras metodologías tradicionalmente utilizadas en el campo de los derechos humanos. Implica examinar el cumplimiento de los estándares mínimos de derechos humanos a partir del criterio de su logro progresivo, tomando períodos de tiempo suficientemente prolongados como para valorar si se producen o no avances concretos en su realización.

Esta idea no es reciente, aunque sí lo es su instrumentación regional. Ya a mediados de los noventas, el entonces Director Ejecutivo del IIDH, profesor Antonio A. Cançado Trindade -después Presidente y actualmente Juez de la Corte Interamericana de Derechos Humanos- lanzó las primeras inquietudes sobre la importancia de hacer mediciones de derechos humanos en forma colateral con la manera tradicional de monitoreo.

En este artículo se presenta una explicación del sentido de tal enfoque, una descripción de los principales aspectos metodológicos y de aplicación del trabajo realizado hasta la fecha, y una síntesis de las conclusiones y recomendaciones de los primeros dos informes sobre la Educación en Derechos Humanos en diecinueve países del continente americano.

\section{Los Enfoques en la Investigación sobre Derechos Humanos}

El enfoque más tradicional (en el sentido de más antiguo y más extendido) en la investigación de temas de derechos humanos es el de la violación. Esto es, aquél que privilegia la identificación de casos de violación, los documenta, discute los aspectos legales y procesales, busca establecer responsabilidades y, en última instancia contribuye a denunciarlos y perseguirlos. Por la naturaleza del objeto de investigación, su metodología es fundamentalmente casuística y resulta muy apropiado para trabajar en el terreno de los derechos civiles y políticos.

Ejemplos de este tipo de investigación -y de sus resultados- son las que realizan periódicamente varias organizaciones no gubernamentales (ONGs) dedicadas a la protección de derechos humanos, tales como Amnistía Internacional o Human Rights Watch en lo internacional y un buen número de las que trabajan en el ámbito nacional y local. En el sector de las instituciones públicas, el trabajo de investigación de las oficinas del Ombudsman (Comisiones, Defensorías y Procuradurías de Derechos Humanos) comparte este enfoque a partir del registro y análisis de quejas de violación.

Este tipo de investigación ha sido y es crucial para denunciar casos específicos de vulneración de derechos, lo cual permite poner en marcha procesos jurídicos y sociopolíticos dirigidos a esclarecer la verdad sobre las violaciones, castigar a los violadores, y ofrecer justicia y reparación a las víctimas, así como para prevenir futuras violaciones. A lo largo de los años, las investigaciones enfocadas sobre violaciones de derechos humanos han diversificado y especializado sus campos temáticos, han desarrollado instrumentos metodológicos cada vez más agudos y han avanzado desde el trabajo sobre casos hacia la identificación de tendencias y de causas estructurales. Evidentemente este enfoque se ha visto favorecido por la ampliación del acceso a la información ligado a la recuperación de la democracia.

Otro enfoque recurrente para la investigación en este campo es el análisis de situaciones de derechos humanos. Este enfoque pone atención, principalmente, en los efec- 
tos sociales acumulados del comportamiento del sector público respecto de sus obligaciones de respetar determinadas condiciones y garantías, o de promover medidas que hagan posible el acceso a los derechos fundamentales sin discriminación. Es un tipo de investigación que combina consideraciones sobre los estándares de derechos humanos con información estadística que describe o analiza situaciones generales, o refleja opiniones generalizadas.

Esta segunda forma de medición privilegia el análisis de correlaciones entre resultados estadísticos y medidas de política pública en campos relacionados con derechos humanos, y se auxilia muy bien con el uso de sistemas de indicadores y con la construcción de índices. Se aplica con ventaja para los campos relacionados con la participación política y el acceso a los derechos económicos, sociales y culturales (DESC).

Este estilo de investigación caracteriza el trabajo de varios órganos de los sistemas internacional e interamericano de protección de los derechos humanos, en particular el que realizan las Comisiones, los Comités especializados y los Relatores especiales. Otros organismos especializados del sistema de Naciones Unidas realizan regularmente estas mediciones y las relacionan con estándares de derechos humanos o, por lo menos, con compromisos gubernamentales surgidos de acuerdos multilaterales. En años recientes, este tipo de investigación se viene aplicando sistemáticamente para el examen de la calidad de la democracia, combinando información estadística de los procesos electorales, con opiniones de especialistas o de paneles de expertos e, inclusive, con resultados de encuestas.

Tal tipo de investigación, que podemos denominar situacional, se ha convertido en una herramienta clave de planificación, tanto en el ámbito doméstico como el internacional, en la medida en que ofrece resultados diagnósticos basados en situaciones medias (estadísticamente hablando), y buenas pistas sobre la relación entre causas y efectos - de los déficit de atención, por ejemplo. Los resultados de las investigaciones así concebidas facilitan la formulación de recomendaciones de acción publica, muchas de las cuales tienen que ver con aspectos legales, institucionales y de asignación de inversión pública. En años recientes, este enfoque se complementa eficazmente con la documentación de buenas prácticas y experiencias exitosas.

Otro enfoque posible, desarrollado a partir de la acumulación y comparación de resultados de investigaciones de situación, busca establecer las variaciones producidas a lo largo del tiempo en determinados campos de derechos humanos. Por asociación con el principio de progresividad de la realización de los derechos - principalmente los económicos y sociales-, denominamos a éste un enfoque de progreso. A él nos referimos en mayor extensión en las siguientes secciones.

\section{Informes y Monitoreo de Derechos Humanos}

El destino más frecuente de los resultados de los distintos tipos de investigaciones sobre derechos humanos ha sido y continúa siendo la preparación de informes. En el sistema internacional de protección, la presentación de informes por parte de los estados, su examen por parte de los órganos de supervisión y la generación de recomendaciones constituye el mecanismo de monitoreo preferente sobre las situaciones en el campo de 
los derechos humanos en general, o de determinados conjuntos de derechos, dependiendo del alcance de los instrumentos internacionales y por tanto de los compromisos asumidos multilateralmente. Algunos de tales instrumentos posibilitan la generación de informes unilaterales, es decir, decididos por los propios órganos de protección-como es el caso de los informes que preparan sistemáticamente los relatores, o los que resultan de visitas in loco para propósitos determinados. Estos informes oficiales reflejan o recogen, según el caso, el punto de vista de los gobiernos sobre las situaciones y sobre los esfuerzos que realizan para cumplir los compromisos convencionales.

Por su parte, una importante constelación de entidades civiles internacionales y varias coaliciones nacionales de organizaciones no gubernamentales también vierten los resultados de sus investigaciones en informes periódicos, generales o especializados, que en algunos casos son ofrecidos y aceptados como material complementario por los órganos de supervisión. Son los llamados "informes sombra”. En estos informes es más frecuente encontrar análisis sobre violaciones recurrentes, limitaciones en el cumplimiento de las obligaciones por parte de los estados y prevalencia de situaciones de riesgo.

En años recientes, el establecimiento de las instituciones del Ombudsman ha dado origen a un nuevo tipo de informe. Es el que el titular de la institución (Defensor, Procurador o Comisionado de Derechos Humanos) debe presentar periódicamente al organismo legislativo, en tanto órgano de control de la constitucionalidad y de los compromisos internacionales en materia de derechos humanos. Estos informes regularmente reportan y analizan quejas recibidas por la institución, o situaciones críticas que han sido objeto de su intervención, así como sobre el efecto y cumplimiento de sus recomendaciones a los agentes del sector público.

No se han desarrollado, con muy contadas excepciones, mecanismos sistemáticos de monitoreo del cumplimiento de las recomendaciones de los órganos internacionales de supervisión ni, mucho menos, de las sentencias de los órganos jurisdiccionales.

Organizaciones especializadas del Sistema de Naciones Unidas y del Sistema Interamericano, a cargo de temas específicos como salud, educación, desarrollo, o de problemáticas atinentes a sectores de población, como mujeres, niños y niñas, refugiados o personas que sufren de discapacidades, vienen incorporando en sus informes periódicos aspectos relativos al estado de los derechos humanos concernidos con el campo de su mandato. El Informe de Desarrollo Humano del Programa de Naciones Unidas para el Desarrollo es un excelente ejemplo de esta tendencia.

Estos procedimientos típicos de monitoreo quedan mejor ilustrados en las previsiones del Protocolo Adicional a la Convención Americana en materia de Derechos Económicos, Sociales y Culturales o Protocolo de San Salvador. Este instrumento considera la presentación de informes como el único mecanismo de protección e implementación para todos los derechos de esa naturaleza que el Protocolo consagra, salvo el caso de los derechos de los trabajadores a organizarse o afiliarse a sindicatos de su elección y el derecho a la educación, que son pasibles también del sistema de peticiones individuales dispuesto por la Convención Americana sobre Derechos Humanos.

Corresponde a los Estados ratificantes del Protocolo someter dichos Informes periódicos a la Secretaría General de la OEA para que los transmita al Consejo Interamericano Económico y Social y al Consejo Interamericano para la Educación, la Ciencia y 
la Cultura a fin de ser examinados. Una copia de tales informes debe ser enviada a la Comisión Interamericana de Derechos Humanos (Art. 19.2, Protocolo de San Salvador).

Por otra parte, el Protocolo faculta a los organismos especializados del Sistema Interamericano a presentar al Consejo Interamericano Económico y Social y al Consejo Interamericano para la Educación, la Ciencia y la Cultura, informes relativos al cumplimiento de las disposiciones del Protocolo, en el campo de sus actividades (Art. 19.4, Protocolo de San Salvador).

De conformidad con una práctica internacionalmente reconocida, se puede suponer que en el sistema regional reciba también informes paralelos -los ya mencionados "informes sombra"- producidos por organizaciones de la sociedad civil, con el fin de cotejar y contrastar la información sometida por los Estados.

Ahora bien, el Protocolo de San Salvador fue adoptado en 1988, hasta la fecha ha sido suscrito por 19 países de la región y ratificado por 13 de ellos. Está en vigencia desde la duodécima ratificación, ocurrida en el año 2000, pero no se han desarrollado aún los instrumentos reglamentarios sobre el sistema de supervisión. Sin embargo, aún cuando los efectos jurídicos del Protocolo de San Salvador se proyectan a partir de la ratificación por los estados firmantes, no por ello su firma carece de eficacia jurídica. Es válido entender que los estados que lo han suscrito tienen una responsabilidad progresiva de ratificarlo, de adecuar su derecho interno, y de diseñar políticas públicas acordes, todo lo cual representa más que un mero compromiso moral. En otras palabras, al firmar el Protocolo han asumido un compromiso proactivo por sentar la plataforma jurídica y logística para promover y proteger los DESC en todas sus dimensiones.

\section{Un Nuevo Enfoque: la Medición de Progresos}

\section{Nuevos Instrumentos para Nuevos Escenarios}

La inquietud por encontrar nuevos enfoques para la investigación y el monitoreo en derechos humanos, surge de constatar las importantes modificaciones que se han dado en el escenario de los derechos humanos en los pasados veinte años y de la necesidad de fomentar el diálogo sobre estos procesos.

En efecto, el marco normativo internacional sobre derechos humanos se ha ampliado notablemente. La ratificación y la recepción de tales avances en la constitucionalidad de los países es mayor; la democracia se ha consolidado formalmente; han surgido entidades gubernamentales de derechos humanos; se están produciendo reformas en los sistemas de administración de justicia y en la educación; se impulsan programas de formación en derechos humanos para las fuerzas armadas y la policía. La movilización de la sociedad civil en defensa de sus derechos es cada día más vigorosa y las redes de organizaciones no gubernamentales son fuertes, profesionales y más especializadas. $\mathrm{Ha}$ nacido la tercera generación de entidades civiles y la comunidad internacional ha incluído definitivamente el tema de los derechos humanos en la agenda de la cooperación para el desarrollo. 
Estas modificaciones implican, entre otros efectos, la diversificación de los actores públicos y civiles y su interacción; la emergencia de nuevos dramas sociales que reclaman respuestas innovadoras; el énfasis de los donantes de fondos sobre inversiones más directas y más efectivas al nivel de los países; el impulso de nuevos criterios de gestión y de impacto de los proyectos; y la necesidad de fomentar la concertación entre las organizaciones de la sociedad civil, el Estado y la comunidad internacional.

A la vez que el escenario se vuelve más complejo, el trabajo en derechos humanos se torna más exigente. De una parte, hacen falta herramientas que permitan documentar objetivamente los procesos que se vienen dando, identificar las tendencias que éstos muestran y formular estrategias acertadas para incidir en ellos. De otra parte, el diálogo sobre los derechos humanos entre la sociedad civil y el Estado, y de estos actores con la comunidad internacional requiere que, además de la problemática de la violación y la responsabilidad, se incluya el establecimiento de diagnósticos y propósitos compartidos, por lo menos respecto de aquellos asuntos que muestran vacíos recurrentes o senderos prometedores.

Con este objetivo, en el IIDH estamos desarrollando una metodología orientada a medir progresos -o la ausencia de progresos- en materia de derechos humanos, tomando como referente los principales instrumentos internacionales que los consagran y que definen las obligaciones de los estados para hacerlos realidad. Nos empeñamos en construir un sistema de monitoreo objetivo y continuo, que facilite la elaboración de informes o relatorías periódicas sobre distintos derechos humanos, complementarios a los informes generados por otros organismos especializados, pero atendiendo en nuestro caso más hacia factores de cambio y mejoramiento de esos derechos que a establecer estados de situación.

Si bien el IIDH no es un órgano oficial del sistema interamericano sino un organismo internacional autónomo, ha asumido un papel cada vez más protagónico en la promoción de los derechos humanos en la región. La misma Asamblea General de la OEA ha reconocido su trabajo y le ha abierto cada vez mayor espacio para que actúe en cooperación y complementariedad con la Comisión Interamericana de Derechos Humanos, apoyándola en sus funciones de promoción y educación.

Desde el IIDH pretendemos que nuestro Informe Interamericano de la Educación en Derechos Humanos -y otros que podrán generarse como parte de la iniciativa de medir progresos- aporte insumos, a manera de una "relatoría amistosa independiente", a los órganos interamericanos de vigilancia, promoción y protección de los derechos humanos. La naturaleza progresiva de este producto coincide con la progresividad de los informes que deben presentar los estados parte del Protocolo de San Salvador al tenor del artículo 19.

A la vez, aspiramos a ofrecer elementos objetivos de juicio a los organismos competentes del sector público, a las organizaciones civiles que trabajan en los países, y a la comunidad internacional de los derechos humanos, para promover un amplio debate sobre los avances de la educación en derechos humanos, ámbito poco investigado con detenimiento hasta la fecha. 


\section{Medir Progresos: un Enfoque y una Herramienta de Trabajo}

Un enfoque de progreso pretende determinar en qué medida los esfuerzos de la sociedad civil, del Estado y de la comunidad internacional están consiguiendo el objetivo común de lograr el imperio de la democracia y del estado de derecho. No se trata de establecer índices de violaciones de derechos humanos, sino más bien logros, pero siempre apuntando hacia la urgencia de alcanzar metas, de adelantar etapas en el proceso de implementación de políticas públicas que favorezcan el entorno para que la protección de los derechos humanos sea más abarcadora.

El enfoque de medir progresos no sustituye al de vigilancia, denuncia y defensa frente a las violaciones, ni pretende ocultar los rezagos en el logro de las metas deseables. Su novedad reside en el potencial que tiene para comprender las cuestiones de derechos humanos como procesos, es decir, como fenómenos que cambian en el tiempo y no sólo como situaciones, o estados propios de un momento determinado. Este enfoque contribuye a identificar no únicamente las carencias, sino también las posibilidades para superarlas en el mediano y largo plazos, y ayuda a establecer prioridades y estrategias de trabajo compartidas y complementarias entre los diversos actores del escenario social.

Para salvar las distancias entre el carácter general y abstracto de las normas y la naturaleza particular y concreta de las prácticas sociales, y compararlas con fines de medición, tal enfoque propone utilizar un sistema de indicadores -o indicios mensurablesque permitan establecer, con un grado razonable de objetividad, las distancias entre la situación en la realidad y el estándar o meta deseada. Para averiguar si estas distancias se están o no acortando, se aplica el sistema a momentos distintos bajo condiciones equivalentes. El resultado será una medida de las variaciones que se han producido entre uno y otro momento histórico y una evidencia de las tendencias que están presentes en ese proceso.

Aún cuando la definición de indicadores no es unívoca, no hay duda de la utilidad práctica de esa herramienta para mostrar la dirección de algún fenómeno, su signo o síntoma. Es por ello que el IIDH ha centrado esfuerzos en el diseño de indicadores utilizando como directriz la progresividad de los derechos humanos.

\section{La Medición de Progresos dentro de la Misión y Estrategia Institucional del IIDH ${ }^{6}$}

Desde su fundación en 1980 como entidad internacional autónoma de naturaleza académica, los fines del IIDH son la enseñanza, investigación y promoción de los derechos humanos y de todas las disciplinas relativas a ellos con un enfoque multidisciplinario que tome en cuenta, en especial, los problemas de América. (Arts. 1 y 5, Estatuto IIDH).

La misión del IIDH le inhibe de estudiar situaciones concretas, y acusar o denunciar a estados, lo cual es competencia exclusiva de los órganos de protección regional creados a tales efectos: la Comisión y la Corte Interamericana de Derechos Humanos. Sin embargo, no le impide avanzar en la construcción de otros parámetros de medición de derechos humanos que transciendan la denuncia o reclamación, para más bien pro- 
mover una forma distinta de lectura de esos derechos a partir de su desarrollo y avance.

Como mencionamos en la Introducción, en el marco de su mandato fundacional, el IIDH adoptó en el año 2000 una estrategia de promoción activa de los derechos humanos basada en la focalización de sus esfuerzos sobre tres campos temáticos -Acceso a la Justicia, Participación Politica y Educación en Derechos Humanos-, en los que se entrelazan de diversas maneras un amplio conjunto de derechos humanos y todos los actores del escenario social -sociedad civil, Estado y comunidad internacional.

El Instituto escogió mirar esos campos temáticos desde tres perspectivas transversales que, sin ser las únicas posibles, tienen especial relevancia para esclarecer el análisis de problemas endémicos de derechos humanos en nuestro continente: Equidad de Género, Diversidad Étnica, e Interacción Sociedad Civil-Estado. Otra razón del IIDH para priorizar estos tres enfoques transversales es su propia y prolongada tradición de estudios, capacitación y trabajo de incidencia en tales ámbitos.

La implantación de la estrategia institucional se apoya, entre otras acciones educativas y de cooperación, en un programa de investigaciones aplicadas orientado a construir (i) un sistema de indicadores de progresos en los campos temáticos y perspectivas priorizadas, y (ii) mecanismos de monitoreo permanente de los mismos.

\section{Primeras Experiencias de Medición}

\section{Mapas de Progresos en Derechos Humanos}

Cruzando los tres ejes temáticos con las tres perspectivas transversales escogidas como base de la estrategia institucional, en el año 2000 se preparó una primera matriz en la cual resaltan problemas, asuntos, horizontes, que constituyen en definitiva el núcleo de la agenda que al Instituto le interesa desarrollar. Esta identificación permitió escoger las líneas estratégicas del trabajo institucional para los próximos años, así como definir las características del sistema de medición -sus campos temáticos, dominios y variables, a partir de los cuales desarrollamos los indicadores de progreso para el ejercicio de observación y monitoreo.

Con el primer sistema organizado en 3 campos, 9 dominios, 25 variables y 66 indicadores, se recabó información de dos momentos históricos escogidos como referentes para la medición los años 1990 y 2002, respectivamente- con el objetivo de conocer las variaciones que se habrían producido durante ese período de tiempo en la legislación, el marco institucional y las prácticas sociales.

El período de referencia elegido se corresponde con varios fenómenos importantes en el continente: la reinstalación de la democracia en varios países y/o la consolidación de las instituciones democráticas y de su independencia relativa; la adopción de reformas constitucionales, legales y administrativas; y la movilización de la sociedad civil en torno a la plena vigencia de los derechos humanos y el estado de derecho. También se corresponde con la ejecución de programas de reforma educativa, y otras reformas estructurales, en la mayor parte de los países.

Durante los años 2000 y 2001, el esfuerzo de investigación se concentró a modo de estudio piloto en 6 países (Guatemala, México, Nicaragua, Paraguay, Perú y Venezuela), 
con la finalidad de definir y probar la metodología; producir resultados que pudieran ser compartidos y validados, y a la vez fortalecer la capacidad institucional de diseño y aplicación de indicadores. Los resultados de esa primera etapa de investigación aplicada constituyen los primeros 6 Mapas de Progresos en Derechos Humanos, antecedente investigativo del actual Informe Interamericano de la EDH.

El procedimiento seguido en la elaboración de los Mapas de Progresos merece una mención especial por su carácter abierto y ampliamente participativo. Estos rasgos de la metodología que allí se puso a prueba se mantendrán, con sistematicidad creciente, al preparar el Informe Interamericano de la EDH.

En los 6 países piloto en los cuales se llevó a cabo la primera aplicación, el sistema de indicadores fue desarrollado por expertos del IIDH en interacción con numerosas organizaciones no gubernamentales de derechos humanos y con colectivos de mujeres, indígenas, funcionarios públicos, trabajadores de las defensorías y otros activistas de derechos humanos. La interacción fue un camino de ida y vuelta: desde el IIDH propusimos la idea, los principios y los componentes del sistema; recogimos opiniones; presentamos los avances del sistema, y volvimos a recoger opiniones para validarlo.

$\mathrm{Al}$ mismo tiempo, las ediciones XVIII a XX de nuestro anual "Curso Interdisciplinario en Derechos Humanos" (en 2000, 2001 y 2002), a cada una de las cuales asistieron alrededor de 120 participantes de todos los países de la región, constituyeron un laboratorio importante de este proceso, pues los talleres de los cursos permitieron poner a prueba progresivamente el trabajo de investigación. Precisamente, la idea de preparar un Informe Interamericano de la EDH surgió en parte impulsada por el éxito de un pequeño ejercicio práctico que hicimos con los estudiantes del XX Curso Interdisciplinario, en julio de 2002, cuyo eje temático fue la Educación en Derechos Humanos.

Como en todos los cursos y todos los años, solicitamos a los postulantes admitidos un trabajo escrito previo, siguiendo una guía que preparamos para orientarlos. En el XX Curso Interdisciplinario tal trabajo versó sobre educación. Les propusimos utilizar parte del sistema de indicadores que la Unidad de Investigación venía desarrollando y aplicarlo en su propio país. La guía fue bastante detallada, con pautas muy claras, para que todos localizaran la misma información en el ámbito que mejor conocieran (por ejemplo, la educación primaria, secundaria, universitaria, electoral, de escuelas judiciales, policiales y militares, la educación no formal impartida por organizaciones de mujeres, por organizaciones indígenas, etc.) El resultado fue muy productivo y nos permitió disponer de una buena cantidad de datos iniciales sobre todo el continente.

A partir de este hecho y del gran entusiasmo generado en el XX Curso Interdisciplinario, surgieron un buen número de nuevas ideas por emprender. Un mes después de finalizado el XX Curso, en agosto de 2002, el Director Ejecutivo del IIDH, Roberto Cuéllar M., propuso la iniciativa de elaborar un informe de alcance interamericano sobre el progreso de la educación en derechos humanos, a la manera de una "relatoría amistosa" que se podría ofrecer a la Comisión Interamericana de Derechos Humanos y, en general, a la comunidad de educadores y personas interesadas en la materia.

La puesta en práctica estuvo a cargo de la Unidad de Investigaciones Aplicadas, con el apoyo de la Unidad Pedagógica. El I Informe Interamericano de la EDH fue presentado el 10 de diciembre de 2002 coincidiendo con la celebración del Día de los Dere- 
chos Humanos, en la sede del IIDH en San José, Costa Rica, y en forma simultánea en varios de los países incluidos en el estudio.

\section{La Medición de Progresos en Educación en Derechos Humanos}

\section{El Derecho a la Educación en Derechos}

El IIDH entiende por Educación en Derechos Humanos (EDH) la posibilidad real de todas las personas - independientemente de su sexo, edad, ocupación, origen nacional o étnico y condiciones económicas, sociales o culturales-de recibir educación sistemática, amplia y de buena calidad que les permita:

- comprender sus derechos humanos y sus respectivas responsabilidades;

- respetar y proteger los derechos humanos de otras personas;

- entender la interrelación entre derechos humanos, estado de derecho y gobierno democrático, y

- ejercitar en su interacción diaria valores, actitudes y conductas coherentes con los derechos humanos y la vida en democracia.

Concebimos la EDH como un derecho, a su vez componente obligado del contenido del Derecho a la Educación, y como condición necesaria para el ejercicio efectivo de todos los derechos humanos. La abordamos con visión de conjunto, articulando distintas perspectivas de análisis, porque lo educativo en general y la EDH en particular, es un campo muy vasto donde interactúan muchas variables: lo jurídico, lo económico, lo socio-político, lo cultural y lo típicamente pedagógico.

Así entendido, el derecho a la EDH requiere de un programa de desarrollo, y por ende de medición, que no puede agotarse en cifras estáticas o proyecciones macroeconómicas. Al contrario, necesita de investigaciones y estudios que examinen las bases filosóficas y normativas de los sistemas de educación formal, las políticas educativas nacionales, los contenidos y metodologías educativas, y la preparación de los agentes educativos, entre otros aspectos que hacen a la cobertura, equidad y calidad de la formación que reciben los niños, niñas y jóvenes.

La definición del campo de la EDH se fundamenta en un buen número de instrumentos internacionales que retoman y profundizan los ideales educativos plasmados en la Declaración Universal de Derechos Humanos (cfr. CUADRO 1).

\section{CUADRO 1: La educación en la Declaración Universal de Derechos Humanos}

\section{Preámbulo}

La Asamblea General

Proclama la presente Declaración Universal de Derechos Humanos como ideal común por el que todos los pueblos y naciones deben esforzarse, a fin de que tanto los individuos como las instituciones, inspirándose constantemente en ella, promuevan, mediante la enseñanza y la 
educación, el respeto a estos derechos y libertades, y aseguren, por medidas progresivas de carácter nacional e internacional, su reconocimiento y aplicación universales y efectivos, tanto entre los pueblos de los Estados miembros como entre los de los territorios colocados bajo su jurisdicción.

\section{Art. 26, inciso 2}

La educación tendrá por objeto el pleno desarrollo de la personalidad humana y el fortalecimiento del respeto a los derechos humanos y a las libertades fundamentales; favorecerá la comprensión, la tolerancia y la amistad entre todas las naciones y todos los grupos étnicos o religiosos; y promoverá el desarrollo de las actividades de las Naciones Unidas para el mantenimiento de la paz.

Asamblea General de las Naciones Unidad, 10 de diciembre de 1948 (negrita de los autores)

La más temprana formulación del núcleo central del derecho a una "educación que fortalezca el respeto por los derechos humanos y las libertades fundamentales y fomente la comprensión, la tolerancia y la amistad entre todas las naciones y todos los grupos raciales y religiosos", se encuentra en la Convención relativa a la lucha contra las discriminaciones en la esfera de la enseñanza, adoptada por la Conferencia General de UNESCO en 1960. A partir de entonces esta fórmula se reitera, con pequeñas modificaciones, en la Convención internacional sobre la eliminación de todas las formas de discriminación racial (1965), en el Pacto Internacional de derechos económicos, sociales y culturales (1966), en el Protocolo adicional a la Convención Americana sobre derechos humanos en materia de derechos económicos, sociales y culturales o Protocolo de San Salvador (1988) y en la Convención sobre los derechos del niño (1989).

Entre los instrumentos citados, es el Protocolo de San Salvador el que caracteriza con mayor amplitud los diversos componentes de este derecho: marca como orientación básica de la educación "el pleno desarrollo de la personalidad humana y del sentido de su dignidad"; asocia el fortalecimiento de los derechos humanos con "el pluralismo ideológico, las libertades fundamentales, la justicia y la paz"; y asigna a la educación un rol central en la capacitación de las personas "para participar efectivamente en una sociedad democrática y pluralista" (cfr. CUADRO 2).

\section{CUADRO 2: El derecho a la educación en el Protocolo de San Salvador}

\section{Artículo 13}

1. Toda persona tiene derecho a la educación.

2. Los Estados partes en el presente Protocolo convienen en que la educación deberá orientarse hacia el pleno desarrollo de la personalidad humana y del sentido de su dignidad y deberá fortalecer el respeto por los derechos humanos, el pluralismo ideológico, las libertades fundamentales, la justicia y la paz. Convienen, asimismo, en que la educación debe capacitar a todas las personas para participar efectivamente en una sociedad democrática y pluralista, lograr una 
subsistencia digna, favorecer la comprensión, la tolerancia y la amistad entre todas las naciones y todos los grupos raciales, étnicos o religiosos y promover las actividades a favor del mantenimiento de la paz.

3. Los Estados partes en el presente Protocolo reconocen que, con objeto de lograr el pleno ejercicio del derecho a la educación:

a. la enseñanza primaria debe ser obligatoria y asequible a todos gratuitamente;

b. la enseñanza secundaria en sus diferentes formas, incluso la enseñanza secundaria técnica y profesional, debe ser generalizada y hacerse accesible a todos, por cuantos medios sean apropiados, y en particular por la implantación progresiva de la enseñanza gratuita; c. la enseñanza superior debe hacerse igualmente accesible a todos, sobre la base de la capacidad de cada uno, por cuantos medios sean apropiados y, en particular, por la implantación progresiva de la enseñanza gratuita;

d. se deberá fomentar o intensificar, en la medida de lo posible, la educación básica para aquellas personas que no hayan recibido o terminado el ciclo completo de instrucción primaria;

e. se deberán establecer programas de enseñanza diferenciada para los minusválidos a fin de proporcionar una especial instrucción y formación a personas con impedimentos físicos o deficiencias mentales.

4. Conforme con la legislación interna de los Estados partes, los padres tendrán derecho a escoger el tipo de educación que habrá de darse a sus hijos, siempre que ella se adecue a los principios enunciados precedentemente.

5. Nada de lo dispuesto en este Protocolo se interpretará como una restricción de la libertad de los particulares y entidades para establecer y dirigir instituciones de enseñanza, de acuerdo con la legislación interna de los Estados parte.

La centralidad del Protocolo de San Salvador como instrumento de derechos humanos para la región de las Américas, así como la claridad de sus formulaciones sobre EDH, que fijan auténticos estándares en la materia, justifican que el IIDH lo haya escogido de parámetro para establecer los alcances del Informe Interamericano de la EDH. Fue nuestro referente a la hora de delimitar el universo por estudiar y, más tarde, de escoger los ejes principales para leer analíticamente los contenidos desplegados en los currículos y textos escolares.

\section{Alcance y Naturaleza del Informe Interamericano de la Educación en Derechos Humanos}

Desde el momento en que comenzamos a diseñar el sistema de indicadores de progreso en el año 2000, para el campo temático de la EDH decidimos examinar todos aquellos factores que la teoría y la práctica pedagógica señalan como los grandes pilares en que se apoya cualquier trabajo educativo-lo que después llamamos los "dominios de investigación”. El CUADRO 3 resume nuestro esquema inicial de abordaje. 
CUADRO 3: Propuesta preliminar para la medición de progreso en Educación en Derechos Humanos

\section{Categorías y variables}

\section{Criterios para definir} indicadores

\section{MARCO LEGAL}

Incorporación de la EDH dentro del ordenamiento del sistema escolar nacional.
Presencia y amplitud de normas y lineamientos explícitos sobre EDH en las leyes de educación y otros documentos oficiales.
Análisis de la normativa oficial en materia educativa.

\section{ACCIÓN INSTITUCIONAL}

Incorporación de la EDH en el currículum escolar oficial.
Presencia y amplitud de contenidos de EDH en el currículum de la escuela primaria y secundaria.
Análisis de planes y programas de estudio para nivel primario y secundario.

\section{ACTORES PRINCIPALES}

Formación en EDH a: 1) administradores educativos

2) docentes en servicio Existencia, regularidad y

3) docentes en formación profundidad de acciones de capacitación oficial sobre principios, contenidos y metodologías de $\mathrm{EDH}$ a: 1) técnicos y supervisores ministeriales y directores de escuelas y colegios 2) maestros y profesores en ejercicio en escuelas y colegios.
Análisis de programas ministeriales de capacitación docente. Duración, periodicidad y características.

Cantidad y distribución de docentes capacitados.
Existencia y profundidad de principios, contenidos y metodologías de EDH dentro de los programas de formación de docentes (Escuelas Normales, Institutos Superiores de Magisterio o Facultades de Educación)
Análisis de los pensum en Escuelas Normales, Institutos y Facultades de Educación. 


\section{ACTORES COMPLEMENTARIOS}

Formación en EDH a:

- padres de familia,

- funcionarios de poderes del Estado,

- líderes comunitarios, comunicadores sociales, etc.
Existencia y regularidad de acciones planificadas de capacitación (formal y no formal) a distintos actores sociales, por parte de:

1) Estado

2) Organizaciones de la sociedad civil
Análisis de las acciones ministeriales de capacitación a otros actores sociales, aparte de docentes. Cantidad y distribución de beneficiarios.

Análisis de acciones de otras organizaciones estatales y de entidades de la sociedad civil en la materia.

\section{INSTRUMENTOS DE APLICACIÓN}

Existencia de materiales didácticos que aborden la EDH.
Variedad y calidad de materiales didácticos disponibles en el país para apoyar la EDH (formal y no formal)

Presencia y énfasis en valores, principios, actitudes y conductas coherentes con los DH y la democracia.

Transversalidad de las perspectivas de género, diversidad étnica y participación de la sociedad civil.
Cuantificación y estimación de pertinencia y calidad de materiales didácticos existentes.

Distinción entre materiales importados (adoptados o adaptados) y de producción local.

Análisis de contenido de los materiales más usados.

\section{INVESTIGACIÓN}

Existencia de estudios sobre educación y derechos humanos.
Número, variedad y difusión de estudios de investigación (conceptual o aplicada) sobre temas de educación y derechos humanos.
Cualificación y revisión temática de estudios producidos en el país. 
Decidimos centrar el estudio en los 19 países que suscribieron y/o ratificaron el Protocolo (cfr. CUADRO 4) por cuanto, al hacerlo, estos estados asumieron el compromiso de llevar esos acuerdos a la práctica, acuerdos que incluyen, entre otros, la aplicación progresiva de las disposiciones del Art. 13 sobre el derecho a la educación y la educación en derechos.

CUADRO 4: Suscripciones y ratificaciones del Protocolo de San Salvador

\begin{tabular}{lcc}
\hline País & Fecha de Suscripción & Fecha de Ratificación \\
\hline Argentina & 1988 & 2003 \\
Bolivia & 1988 & --- \\
Brasil & & 1996 \\
Colombia & & 1997 \\
Costa Rica & 1988 & 1999 \\
Chile & 2001 & --- \\
Ecuador & 1988 & 1999 \\
El Salvador & 1988 & 1995 \\
Guatemala & 1988 & 2000 \\
Haití & 1988 & --- \\
México & 1988 & 1996 \\
Nicaragua & 1988 & --- \\
Panamá & 1988 & 1992 \\
Paraguay & 1996 & 1997 \\
Perú & 1988 & 1995 \\
República Dominicana & 1988 & --- \\
Suriname & & 1990 \\
Uruguay & 1988 & 1995 \\
Venezuela & 1989 & --- \\
\hline
\end{tabular}

Fuente: www.oas.org/juridico/spanish/firmas/

Un aspecto que explicitamos claramente desde el inicio de la elaboración del Informe Interamericano de la $E D H$ fue su particular naturaleza explicando no solamente lo que el Informe es, sino también lo que no es, ni pretende ser.

No se trata un informe sobre el derecho a la educación, sino sobre el derecho a la educación en derechos humanos. Se centra en objetivos no estudiados por otros informes que analizan el acceso a los servicios educativos sin discriminaciones, e indaga sobre un aspecto particular de los servicios educativos: la incorporación de principios y contenidos sobre derechos humanos. Por tanto, no sustituye sino complementa otros tipos de informes. 
Tampoco es un "informe sombra", como los elaborados por organizaciones de la sociedad civil con el propósito de cotejar y contrastar los datos contenidos en los informes periódicos de los estados ante los órganos del sistema interamericano. Es una propuesta surgida de los fines y competencias propias del IIDH como institución orientada a la $\mathrm{EDH}$, a la que no le compete juzgar las acciones de los estados. Busca ofrecer herramientas que permitan evaluar la marcha de los procesos de incorporación de los derechos humanos en la vida política y social de los países de la región, según se deriva de los compromisos asumidos ante la comunidad internacional.

\section{Proceso de Elaboración: Plan deTrabajo y Precisiones Metodológicas}

En vista de la diversidad de factores por examinar, sumado a la complejidad intrínseca de cada uno de ellos, se adoptó un plan de trabajo progresivo en cuatro etapas, que analizaría uno o dos conjuntos de variables (dominios) por año. Resolvimos producir un Informe anual, parte de una serie total de cuatro, con la intención de volver a empezar el ciclo una vez concluida la primera ronda.

El objetivo general de la serie fue investigar las variaciones producidas respecto a la incorporación de la $\mathrm{EDH}$ en la educación formal y no formal de los 19 países en el período de referencia escogido (1990-2002/03), siguiendo en grandes líneas la siguiente secuencia:

\section{Año 2002 - Io Informe:}

Variaciones en el plano normativo -internacional y nacional-, en la adopción de políticas públicas y en el curso de los procesos de reforma educativa.

Año 2003 - IIo Informe:

Variaciones en los lineamientos y orientaciones del currículo educativo, en los contenidos de planes y programas de estudio de nivel primario y secundario, y en los contenidos y forma de presentación de los textos escolares.

\section{Año 2004 - IIIo Informe:}

Variaciones en la capacitación o actualización de educadores en servicio y en la formación profesional de futuros educadores.

\section{Año 2005 - IVo Informe:}

Variaciones en las actividades no formales (no escolares) de $\mathrm{EDH}$ por parte de las organizaciones de la sociedad civil.

Cada etapa del estudio presentó, y sigue presentando, retos particulares derivados de las características propias de los distintos dominios de la investigación. Mientras trabajábamos en los dos primeros informes debimos introducir ajustes o hacer mayores precisiones sobre sus alcances, los respectivos objetos de estudio y el instrumental de medición, o sea, la matriz de indicadores. Lo mismo ocurre con lo que llevamos avanzado del tercer informe, y sin duda ocurrirá con el cuarto. El proceso de investigación va generando así un ir y venir muy dialéctico desde la propuesta-marco inicial de indicadores —la que se usó en los Mapas de Progresos en 2000 y 2001- hacia las posibilidades de aplicación en cada dominio del campo temático de la EDH, y de retorno a la 
propuesta-marco para afinarla como un sistema paulatinamente más comprehensivo y articulado.

Los ajustes y precisiones que introdujimos fueron de distinto tipo. En el caso del Io Informe (las variaciones en el plano normativo), vimos la necesidad de expandir la matriz original a efectos de recoger mayor cantidad de información relevante. Por ejemplo, aparte del análisis de las ratificaciones de instrumentos internacionales que hacen referencia a la $\mathrm{EDH}$, las constituciones políticas y las leyes generales de educación, añadimos el de otras leyes especiales aprobadas durante la década que incluyen menciones y objetivos sobre EDH o temas afines como la educación para la democracia, educación cívica, en valores, etc. Entre ellas, las leyes de creación del Ombudsman, de reforma a planes de formación judicial, policial y/o militar y de educación multicultural y bilingüe.

Al comprobar la inserción de la EDH en varios órdenes de la legislación interna de los países estudiados, se reforzó la asociación explicativa entre los cambios normativos identificados y varios fenómenos característicos de la época estudiada, tales como la reinstalación de la democracia en un buen número de países de la región, los acuerdos de paz que pusieron fin a conflictos internos en otros, y, en la gran mayoría, la consolidación de las instituciones democráticas y la movilización de la sociedad civil tras la plena vigencia de los derechos humanos y el estado de derecho.

El Io Informe también se expandió con los datos comparados de las previsiones legales sobre acceso, financiamiento, obligatoriedad y cobertura de la educación sistemática en los países estudiados. Estos indicadores son claves para hacer una primera lectura de las normativas nacionales sobre educación desde una perspectiva de derechos humanos.

La matriz del $I I^{\circ}$ informe se presenta en el siguiente cuadro:

CUADRO 5: Matriz utilizada para la preparación del Io Informe

\begin{tabular}{|c|c|}
\hline Variable & Indicador y medio de verificación \\
\hline 1. Adopción de Normas sobre EDH & $\begin{array}{l}\text { 1: ratificación de Instrumentos Internacionales. } \\
\text { 2: inclusión de EDH en las leyes del régimen nacional. }\end{array}$ \\
\hline 2. Adopción de Políticas Públicas & $\begin{array}{l}\text { 1: existencia de Decretos, Resoluciones y otros instru- } \\
\text { mentos de administración publica. } \\
\text { 2: inclusión de EDH en documentos oficiales (Reforma } \\
\text { Educativa, p.e.) y planes de Educación. }\end{array}$ \\
\hline 3. Desarrollo Institucional & $\begin{array}{l}\text { 1: existencia de dependencias gubernamentales } \\
\text { especializadas en EDH. } \\
\text { 2: programas gubernamentales especializados en EDH. }\end{array}$ \\
\hline $\begin{array}{l}\text { 4. Derecho a la Educación } \\
\text { (como contexto) }\end{array}$ & $\begin{array}{l}\text { 1: en las normas constitucionales. } \\
\text { 2: porcentaje constitucional del Presupuesto Nacional } \\
\quad \text { para la Educación } \\
\text { 3: obligatoriedad de la Educación } \\
\text { 4: matrícula educativa }\end{array}$ \\
\hline
\end{tabular}


A diferencia del $I^{o}$ Informe, los ajustes introducidos durante el proceso de elaborar el $I I^{\circ}$ Informe se orientaron sobre todo a delimitar y focalizar la matriz original, en aras de abordar los dominios de investigación con mayor profundidad.

Optamos entonces por concentrarnos en una población estudiantil específica, la que se encuentra en el rango de 10 a 16 años de edad, y de entre los grados escolares que cursa este grupo etario, seleccionamos como muestra el $5^{\circ}$, el $8^{\circ}$ y el $11^{\circ}$. Del conjunto de asignaturas del plan de estudios de $5^{\circ}, 8^{\circ}$ y $11^{\circ}$ grados se seleccionaron aquellas que, por la naturaleza de la disciplina, ofrecían mayores probabilidades de incorporar contenidos, principios y lineamientos metodológicos de EDH. Los cursos escogidos fueron "Estudios Sociales" y "Educación Cívica", o sus equivalentes ("Ciencias Sociales", "Sociología", "Historia" "Realidad Nacional", "Educación Democrática", etc., según la denominación que se use en cada país).

Estas opciones por un grupo de edad, determinadas materias del programa escolar y algunos grados escolares implican determinaciones que ilustran en parte la orientación, la naturaleza y los límites de este esfuerzo institucional. Asumimos que el grupo de edad en el cual la EDH podría resultar más eficaz es el que coincide con el periodo de desarrollo psicosocial en el cual los y las jóvenes desarrollan su sentido de alteridad, esto es, reconocen y diferencian con mayor profundidad su identidad y la identidad del "otro" y por tanto son más susceptibles a adquirir nociones de derechos y obligaciones mutuas.

Escogimos al azar tres grados escolares intercalados para reducir el tamaño del universo de estudio durante la recolección de información, con la advertencia de que, si fuera evidente que los contenidos de EDH estuvieran localizados en otros grados intermedios, se debían registrar. Finalmente, por la misma razón de economía del proceso de registro, apuntamos hacia las asignaturas en las que de manera más evidente podrían aparecer estos contenidos.

Predefinimos también algunos ejes conceptuales que, cual plano de navegación, guiarían el recorrido analítico a través de la enorme cantidad de información desplegada en los programas y libros de estudio de esas asignaturas -sin pretender, no obstante, agotar con ellos el vasto espectro temático de la EDH. Los ejes fueron:

1. Derechos humanos y garantías constitucionales.

2. Justicia, instituciones del Estado y Estado de Derecho.

3. Democracia, derecho al voto, elecciones y pluralismo político e ideológico.

4. Educación en valores (solidaridad, dignidad humana, paz, tolerancia y comprensión entre las naciones).

5. Equidad de género.

6. Diversidad étnica.

7. Interacción de la sociedad civil y el Estado.

La selección de estos ejes integra tanto las calidades que debería tener la EDH de conformidad con el texto del numeral segundo del artículo 13 del Protocolo de San Salvador, como los elementos constitutivos de la definición sobre EDH adoptada por el IIDH y su estrategia institucional de trabajo. Asimismo, fue consultada con grupos de 
trabajo y especialistas en la materia, quienes contribuyeron a seleccionar los aspectos que, según su experiencia, expresarían mejor las aspiraciones de la gente y resultarían indicativos de avances importantes en el proceso de incorporación de los temas de derechos humanos en los instrumentos educativos.

Localizar el estudio en una muestra de grados y asignaturas escolares, así como utilizar ejes conceptuales para hacer una lectura transversal de contenidos, permitió prestar atención a las variadas formas en que los instrumentos educativos ponen de manifiesto una visión de la persona humana y del mundo social. Paralelamente al análisis del discurso verbal explícito de las orientaciones curriculares, los programas de estudio y los textos escolares, examinamos si estos instrumentos eran o no sensibles a la equidad de género y a la no-discriminación étnica con respecto al lenguaje usado, a la construcción de las imágenes en los libros y a los roles que se asignan a los diversos actores en los ejemplos e ilustraciones didácticos. Este análisis contribuyó a establecer el grado y la solidez de los avances alcanzados en la incorporación de la EDH, así como también a identificar lagunas, e incluso inconsistencias.

El diseño final del sistema de dominios, variables e indicadores para el IIo Informe se resume en el siguiente cuadro:

CUADRO 6: Matriz utilizada para la preparación del IIo Informe

\section{Dominio 1: Régimen curricular en 1990 y 2003}

\section{Variable 1:}

Incorporación en el documento oficial que orienta los objetivos y contenidos del currículo

Indicador 1: Contenidos referidos expresamente a derechos humanos y garantías constitucionales.

Indicador 2: Contenidos referidos expresamente a justicia, instituciones del Estado, el Estado de Derecho

Indicador 3: Contenidos referidos expresamente la democracia, derecho al voto, las elecciones, al pluralismo político e ideológico.

Indicador 4: Contenidos referidos expresamente a educación en valores (solidaridad, dignidad humana, paz, tolerancia y comprensión entre las naciones).

Variable 2:

Incorporación de contenidos en los programas de estudios oficiales de $5^{\circ}, 8^{\circ}$, y $11^{\circ}$ grados
Indicador 1: Contenidos referidos expresamente a derechos humanos y garantías constitucionales.

Indicador 2: Contenidos referidos expresamente a justicia, instituciones del Estado, el Estado de Derecho.

Indicador 3: Contenidos referidos expresamente la democracia, derecho al voto, las elecciones, al pluralismo político e ideológico.

Indicador 4: Contenidos referidos expresamente a educación en valores (solidaridad, dignidad humana, paz, tolerancia y comprensión entre las naciones). 
Dominio 2: Textos educativos en 1990 y 2003

\section{Variable 1:}

Incorporación de contenidos en textos educativos para $5^{\circ}, 8^{\circ} \mathrm{y}$ $11^{\circ}$ grados
Indicador 1: Contenidos referidos expresamente a derechos humanos y garantías constitucionales.

Indicador 2: Contenidos referidos expresamente a justicia, instituciones del Estado, el Estado de Derecho.

Indicador 3: Contenidos referidos expresamente la democracia, derecho al voto, las elecciones, al pluralismo político e ideológico.

Indicador 4: Contenidos referidos expresamente a educación en valores (solidaridad, dignidad humana, paz, tolerancia y comprensión entre las naciones).

Dominio 3: Tratamiento de las perspectivas transversales en 1990 y 2003

Variable 1:

Equidad de género
Indicador 1: Contenidos de equidad de género en 1) Documento oficial que fija los objetivos y contenidos del currículo 2) Programas de Estudios 3) Textos Educativos.

Indicador 2: Lenguaje que se utiliza en los textos educativos. Indicador 3: Rol que ocupa la mujer en las imágenes de los textos educativos.

Indicador 4: Número de mujeres en relación a los hombres que se observa en las imágenes de los textos educativos.

Variable 2:

Diversidad étnica
Indicador 1: Contenidos de diversidad étnica en 1) Documento oficial que fija los objetivos y contenidos del currículo 2) Programas de Estudios 3) Textos Educativos.

Indicador 2: Rol que ocupan indígenas y afrodescendientes en las imágenes de los textos educativos.

Indicador 3: Número de indígenas y afrodescendientes en las imágenes de los textos educativos.

Indicador 4: Existencia de bibliografía auxiliar o complementaria sobre la interculturalidad y el bilingüismo.

Indicador 1: Rol de la sociedad civil en el proceso de elaboración del currículo.

Indicador 2: Contenidos en los que se promueva el conocimiento y/o la participación de la sociedad civil en distintas organizaciones gubernamentales y no gubernamentales en Programas de Estudios y Textos Educativos. 
La recolección de la información primaria de cada país para producir los Informes fue realizada por consultores locales, seleccionados en su mayor parte entre los ex alumnos del XX y XXI Curso Interdisciplinario o de cursos anteriores dictados por el IIDH. Desde la sede del Instituto se acompañó el proceso de investigación y se fomentó una lista de discusión electrónica entre los consultores, con la finalidad de conseguir resultados homologables. El procesamiento de la información y la preparación de las conclusiones estuvieron a cargo del equipo profesional de las Unidades de Investigación y Pedagógica del Instituto en San José. El mismo procedimiento se utilizará para los informes subsiguientes.

La preparación del IIIo Informe, iniciada en enero del 2004, anticipa algunas complejidades aún mayores. A lo largo de los últimos 25 años la formación de los educadores ha dejado de estar a cargo de instituciones especializadas como los institutos normales - y en general de la llamada educación terciaria- para pasar a ser una carrera de la formación superior, en las facultades y escuelas de pedagogía, muchas de las cuales, a la vez, han desplegado un amplio abanico de subespecialidades, (por grupos de edad, por materias, por funciones administrativas o docentes, etc.).

Pero al mismo tiempo, el reclutamiento de educadores se ha ampliado, por varias razones -legales y económicas-, a todo tipo de profesionales, en algunos casos sin mediar siquiera algún entrenamiento ad-hoc para su incorporación al magisterio. La ampliación de la educación privada ha contribuido más aún a la desregulación de este campo, que en algún momento fue altamente controlado por el Estado. En estas condiciones resultará bastante arduo identificar con precisión dónde se formaron los maestros que actualmente enseñan las materias y en los grados escolares seleccionados.

Más aún, resulta que solamente una parte de la formación de los educadores proviene de su historial académico o profesional. Una buena parte de su entrenamiento, especialmente del requerido por los cambios en los planes de estudio, en los programas de las asignaturas y en la producción de nuevos textos escolares, se realiza en actividades de actualización o de entrenamiento en el trabajo, cuya documentación es difícil de obtener, y cuya variación debe ser observada no únicamente en el contraste entre un año inicial (1990) y uno final (2003), sino que debe ser rastreada a lo largo de esos trece años.

La pretensión de establecer una metodología estándar, que sea aplicada simultáneamente en los 19 países y facilite la comparación y el establecimiento de tendencias en el ámbito regional, empieza entonces a ser objeto de excepciones y/o criterios de flexibilización, que podrian amenazar la eficacia del método.

\section{Aprendizajes e Impactos}

\section{Sobre la Focalización Temática y las Perspectivas Transversales}

Las numerosas acciones de consulta y validación durante la fase de diseño del sistema general de indicadores de progreso en derechos humanos, así como las reacciones y comentarios que provocaron los Mapas y los Informes, han mostrado que fueron acer- 
tadas las decisiones de (i) focalizar el trabajo sobre determinados campos temáticos concebidos como conjuntos de derechos y (ii) adoptar un conjunto de perspectivas transversales que reflejen el punto de vista de actores sociales especialmente importantes, en tanto contribuyeron a dar cuenta de una porción significativa del escenario de los derechos humanos y sus principales problemas, y permitieron mejorar, sobre la marcha, el instrumental de trabajo. Asimismo, permitieron constatar un buen nivel de aceptación del enfoque de progreso, siempre bajo la advertencia de que el trabajo de defensa y denuncia sobre violaciones de derechos humanos continúa vigente.

Efectivamente, dada la extensión del escenario y la enorme cantidad y variedad de indicadores que requeriría una medición completa de derechos humanos, el IIDH escogió tres campos temáticos que, de conformidad con su experiencia, sintetizan una porción muy importante de los dramas actuales de la región y, al mismo tiempo, permiten aquilatar las oportunidades de avance. Los resultados obtenidos en los Mapas de progreso y sobre todo la utilización de los mismos como una base de diagnóstico de los países y como elemento para definir y orientar el trabajo institucional, han mostrado su utilidad.

Lo mismo podemos señalar respecto de la concepción de las perspectivas transversales como un mecanismo para incorporar la comprensión de la realidad, intereses y aspiraciones en derechos humanos de los actores.

\section{El Uso de Indicadores}

La investigación consideró que la base del procedimiento de diseño del sistema y de su aplicación es su legitimidad, que se consigue mediante la validación de las opciones metodológicas adoptadas progresivamente por parte de los mismos interesados. Asimismo, estimó conveniente combinar diversos tipos de mecanismos para obtener las informaciones requeridas, sin privilegiar las estadísticas -ciertamente escasas en los campos de nuestro interés.

Finalmente se adoptó la idea de tener en cuenta dos sistemas de estándares: uno básico, representado por las normas internacionales (principalmente las interamericanas) ratificadas por los estados como un compromiso mínimo, y uno superior, que exprese las aspiraciones de la gente en cada campo temático.

La construcción del sistema estuvo sujeta a un proceso de ampliación y selección sucesiva de los campos, las variables y los indicadores, en la búsqueda de un conjunto de elementos que den cuenta, mediante indicios, de los cambios más significativos en cada temática. La selección para el primer ejercicio dio prioridad a indicadores sobre aspectos legales e institucionales para los que podrían utilizarse fuentes secundarias disponibles. Las aplicaciones subsiguientes, realizadas para el Informe Interamericano de la EDH, consideraron otros mecanismos directos de investigación que permitieron recoger opiniones y expectativas de la población.

Aunque el avance en la discusión conceptual sobre las perspectivas transversales es destacable, el esfuerzo inicial no fue suficiente para trasladar estos aspectos al sistema de indicadores, de tal manera que los resultados de los Mapas de progreso reflejan muy pobremente este aspecto, que es crucial en la estrategia institucional. Para el Informe 
Interamericano de la $E D H$ se establecieron dominios específicos relacionados con las perspectivas transversales, con resultados muy alentadores.

De acuerdo con esta estrategia metodológica fue necesario introducir preguntas, específicamente formuladas para averiguar indicadores sobre equidad de género, diversidad étnica e interacción sociedad civil-Estado, a manera de una segunda lectura de las mismas fuentes de verificación -políticas, programas, textos escolares- para lograr una apreciación complementaria.

La aplicación del sistema tropezó con una dificultad principal, tanto en la investigación piloto para los Mapas de progreso, como en las investigaciones para el Informe de la EDH: la dispersión y la desigualdad de las bases de información, sobre todo las de carácter histórico. Para los Mapas de progreso solamente un 70\% de los indicadores fueron cabalmente documentados. Para un $15 \%$ no se encontró información -al menos en el corto tiempo propuesto para cumplimentar el ejercicio-, y un restante 15\% resultó poco relevante debido a deficiencias de diseño de las matrices, o imprecisión de los datos. Estas cifras mejoraron para el Informe de la EDH; aunque persistió la dificultad para contar con medios de verificación para los años noventa, a pesar de tratarse de documentos de carácter oficial, como los programas y los textos escolares.

En general, la propuesta de utilizar indicadores de progreso para establecer el ritmo y la dirección de la evolución del panorama de los derechos humanos y la democracia ha sido muy bien acogida en la comunidad de derechos humanos. El IIDH ha recibido varios pedidos de asistencia técnica para considerar el uso de esta metodología en la preparación de informes o el establecimiento de sistemas de monitoreo en diversos campos de derechos humanos.

\section{La Perspectiva de Progreso}

Finalmente, cabe señalar que tal como se intuyó al principio, adoptar una perspectiva que pone su primera mirada sobre la cuestión de los avances progresivos en la realización de los derechos humanos, ha permitido desarrollar un concepto que es al mismo tiempo un instrumento para facilitar el diálogo entre los actores en el escenario de los derechos humanos y la democracia.

En efecto, oficiales gubernamentales, activistas en derechos humanos y representantes de la cooperación internacional encuentran más fácil entablar intercambios de opiniones en un espacio relativamente alejado de las tensiones que tradicionalmente los colocaron en bandos enfrentados por la consideración de las violaciones a los derechos humanos. Hay desacuerdos en la valoración de los progresos y los estancamientos, y diversidad de posiciones acerca de las medidas que se deben tomar para remontar brechas, pero hay una clara idea de la necesidad de realizar esfuerzos conjuntos, o al menos complementarios, en torno a aspectos fundamentales.

Un campo muy prometedor para el uso de este sistema es, indudablemente, el de los DESC. Se trata de un campo en el cual la existencia de información estadística, la construcción de indicadores e incluso la formulación de índices sobre situaciones sociales concretas están muy avanzadas, pero la correlación de estos resultados con los dere- 
chos correspondientes -y por tanto con el progreso en el cumplimiento de los compromisos de los estados_- requieren un desarrollo más sutil. La aplicación de esta metodología al campo de los DESC probablemente contribuirá a establecer más claramente la relación entre estos derechos - llamados de desarrollo progresivo- con dificultades persistentes en el campo de los derechos civiles y políticos, tales como la discriminación, la exclusión y la inequidad.

\section{Anexos}

\section{Conclusiones y Recomendaciones del I Informe Interamericano de la Educación en Derechos Humanos (2002) Conclusiones \\ Sobre Aspectos Conceptuales y Contextuales:}

El concepto de educación en derechos humanos debe ser entendido como perspectiva transversal del derecho a la educación y debe estar presente en todas las formas posibles de enseñanza formal e informal para que pueda ser elemento inclusivo de una cultura de derechos humanos. Su definición y contenidos han sufrido un proceso de constante evolución y progresividad desde que fueron incorporados en la Declaración Universal de los Derechos Humanos y posteriormente desarrollados por subsiguientes instrumentos internacionales e implementados por Constituciones Políticas y legislación interna acompañada por programas y planes en los países que conforman este informe.

\section{Sobre Adopción de Normas Internacionales:}

Los instrumentos internacionales que se han mencionado en este informe configuran progresivamente -a lo largo de cuarenta años- el derecho de todas las personas y la obligación de los Estados a favor del establecimiento de la educación en derechos humanos entendida en un sentido cada vez más profundo, que toca a las libertades civiles, al ejercicio de la democracia y al logro de los derechos económicos, sociales y culturales.

Así mismo este desarrollo amplía y especializa progresivamente el derecho a la educación en derechos humanos en favor de sectores sociales que en razón de sus especificidades requieren de acciones afirmativas para promover, recuperar o proteger de modo más directo sus derechos específicos, que son precondición del disfrute de los derechos y libertades fundamentales: tales los casos de las mujeres, los niños, los pueblos indígenas, las personas que sufren algún tipo de discapacidad o se encuentran privadas de libertad.

Los primeros instrumentos fijan compromisos genéricos relativos a la adopción de políticas educativas. Los más recientes comprometen el establecimiento de programas, campañas y servicios permanentes, revisar y corregir libros de texto y otros materiales didácticos, producir traducciones en las lenguas indígenas, educar y capacitar a los operadores jurídicos, a los encargados del orden público y a otros funcionarios responsables de velar por el ejercicio de los derechos humanos. 
El estado de la ratificación de los instrumentos internacionales permite señalar que los 19 países objeto de este informe, han tomado el compromiso de orientar sus políticas educativas en dirección al fortalecimiento de los derechos humanos y las libertades fundamentales, así como al combate contra la discriminación racial y contra las mujeres. Todos ratificaron la Convención sobre derechos del niño. Más de la mitad han ratificado las convenciones que, como el Protocolo de San Salvador, amplían significativamente la definición hacia la educación para la democracia y la paz y demandan la puesta en marcha de medidas y acciones específicas.

Por lo menos cinco países en cuyos territorios viven pueblos indígenas no han ratificado todavía el Convenio $\mathrm{N}^{\circ} 169$ de la OIT. Todas las ratificaciones faltantes son importantes, pero es particularmente preocupante el rezago que muestra la ratificación del Protocolo de San Salvador.

\section{Sobre Constituciones:}

En la década estudiada aumenta en forma considerable la incorporación de principios y/o contenidos de EDH en las constituciones nacionales, ya sea en forma explícita o implícita. Esta tendencia parece continuar y expandir un movimiento que comenzó en la década anterior -la de los años ochenta-, porque varios países que en 1990 ya contaban con una caracterización bastante amplia de la educación la habían introducido en reformas constitucionales recientes (entre ellos, por ejemplo, Ecuador, El Salvador, Guatemala, México, Panamá y Perú).

Además se evidencia una macro-tendencia a enriquecer la caracterización de la educación. Esto lo interpretamos como un progreso en materia educativa, que se asocia con un progreso normativo de la $\mathrm{EDH}$ en la región. Es cuando se enriquece la visión de la educación, que se van incorporando de manera explícita en las normas constitucionales los principios de la $\mathrm{EDH}$, tales como formar para la vida en democracia, en valores éticos, en el conocimiento y respeto de los derechos humanos y en la diversidad por Esto se da, en la medida que se provee respaldo jurídico a la enseñanza de las lenguas y culturas de los distintos grupos étnicos que conforman la población del país.

\section{Sobre Leyes de Educación:}

En la década estudiada también se incrementa la incorporación de principios y/o contenidos de EDH en las leyes nacionales que regulan la educación en el país.

En síntesis, los procesos de reforma educativa de las dos últimas décadas del siglo XX en los países estudiados, van permeando en forma gradual pero sólida las leyes generales de educación con muchos principios y contenidos de EDH. Resulta interesante observar que algunos de los procesos de reforma más abarcadores (es decir, que modifican de una sola vez más aspectos en el campo de la educación) y donde aparecen con mucho énfasis principios, conocimientos, valores y actitudes de $\mathrm{EDH}$, se produjeron después de que el país realizó la transición de regímenes de gobierno dictatoriales a otros democráticos (por ejemplo, en Argentina y Paraguay), o bien después de la firma de acuerdos de paz que pusieron fin a conflictos armados internos (por ejemplo, en Nicaragua y Guatemala). 
Interpretamos que estos casos reflejan con claridad la intencionalidad política de las reformas educativas porque, más allá de objetivos de modernización del sistema escolar, se está reconociendo el rol central de la educación para construir sociedades más justas, inclusivas y participativas; en suma, más humanas y democráticas.

Vale la pena señalar que hay casos en que no son las leyes generales de educación las que desarrollan normas sobre valoración de la diversidad, educación bilingüe e intercultural y participación de diversos actores sociales en la política educativa. En varios países estos temas suelen aparecer en reglamentaciones y lineamientos ministeriales, o en leyes específicas bastante recientes, o en proyectos de ley en trámite. Sin dejar de reconocer la importancia de que tales temas estén presentes en algún cuerpo normativo nacional, al margen de su nivel, creemos que principios tan relevantes para la EDH quedan reconocidos de modo más integral y mejor garantizados cuando se incorporan en la legislación nacional sobre educación.

\section{Sobre otra Legislación:}

Poco tiempo antes de iniciar la década en estudio, hubo una proliferación de leyes especiales tendientes a fortalecer la reinstalación de la democracia y sus instituciones, el estado de derecho y los derechos humanos (leyes electorales y de partidos políticos, de formación y capacitación policial civil y de fuerzas armadas, leyes a favor de la niñez y de mujeres y creación de instituciones con algún mandato en educación en derechos humanos como las Oficinas de Ombudsman, escuelas judiciales, institutos de la mujer y oficinas y programas para asuntos de pueblos indígenas). Durante el período analizado, estas leyes e instituciones fueron objeto de reformas. Se constató que esa legislación incluye menciones y objetivos sobre $\mathrm{EDH}$ y otros temas afines como educación para la democracia, educación cívica, educación en valores, etc.

La inserción de la EDH en la normativa interna de los países estudiados coincide con varios fenómenos característicos de la época estudiada, como la reinstalación de la democracia en varios de esos países, la consolidación de las instituciones democráticas, la adopción de reformas constitucionales, legales y administrativas y la movilización de la sociedad civil respecto a la plena vigencia de los derechos humanos y el estado de derecho.

\section{Sobre Políticas Públicas y Desarrollo Institucional:}

La promulgación de reformas constitucionales y leyes de educación y otras afines con componentes de $\mathrm{EDH}$ han generado la puesta en marcha de numerosos programas que desarrollan los principios y contenidos en esa materia y el establecimiento de comisiones, comités y otras instancias para impulsarla.

No obstante, no todas esas iniciativas establecen un mandato claro o referencias explícitas al establecimiento de políticas públicas, en el sentido de políticas de Estado, favorables a la EDH. En parte esta característica es compartida con $-\mathrm{y}$ en cierto sentido derivada de - la debilidad relativa de las políticas de derechos humanos en general, si bien en este campo la creación de instancias como las oficinas de ombudsman se han consolidado, en los últimos años, tanto en la esfera legal, como en la de las instituciones. 
Hay una característica de la esfera de las políticas públicas que vale la pena destacar para evitarla: su dispersión. Si bien es cierto que se han identificado numerosos programas y proyectos preocupados por la temática de la $\mathrm{EDH}$, no es evidente que estos hagan, en conjunto, parte de una sola estrategia de promoción. Lo mismo ocurre con las numerosas instancias permanentes $\mathrm{u}$ ocasionales que se han mencionado antes: no conforman una red institucional claramente articulada.

En algunos países se reportan esfuerzos por establecer instancias, con participación de la sociedad civil, que preparen e impulsen planes nacionales de derechos humanos y, ciertamente, tales esfuerzos se preocupan explícitamente de las cuestiones relacionadas con la educación. Sin embargo se trata todavía de propuestas en curso de desarrollo que, si bien responden a las recomendaciones de varios eventos internacionales como las Conferencias de Viena, de Beijín y de Durban, son altamente dependientes de las iniciativas y de los recursos de la cooperación internacional y no han alcanzado hasta ahora la fuerza que le daría un marco legal integral que fortalezca la educación en derechos humanos como una política de Estado, permanente, debidamente financiada e institucionalizada, tal como lo demandan desde hace varios años las organizaciones no gubernamentales y los movimientos sociales.

Los procesos de fortalecimiento de instituciones democráticas y del estado de derecho en la región están acompañados de una tendencia favorable a fortalecer el derecho a la educación en derechos humanos, con puntos más altos en la adopción de normas legales y más bajos en consolidar políticas públicas.

Esos procesos y esta tendencia crean un escenario en el cual sería posible esperar y promover progresos sostenidos en este campo para que, junto con el creciente proceso de participación de la sociedad civil en la promoción y defensa de los derechos humanos, se promueva la EDH como perspectiva transversal de esas dinámicas.

\section{Recomendaciones}

- Instar a los Estados que no lo hayan hecho, a que ratifiquen los instrumentos internacionales específicos que les hace falta para completar los estándares mínimos en materia de $\mathrm{EDH}$ en ellos dispuestos, con el fin de comprometer sus políticas educativas y conexas en ese campo, hacia el fortalecimiento de los derechos humanos en forma integral sin ningún tipo de discriminación racial, de género o de cualquier naturaleza, incluso fomentando acciones de tipo afirmativo a favor de pueblos indígenas y afrodescendientes, mujeres, personas menores de edad y demás grupos que se encuentren en situación de vulnerabilidad y exclusión.

- Continuar el proceso de enriquecimiento progresivo de la EDH mediante reformas constitucionales que impulsen los procesos de adecuación de la legislación interna a los instrumentos internacionales en la materia y, especialmente, respecto a la incorporación de la normativa caracterizada por acciones de tipo afirmativo que favorezca a los sectores de la población comprendidos en las perspectivas transversales de este informe. - Aumentar progresivamente la incorporación de las obligaciones y principios que informan la EDH en las leyes especiales sobre educación y en otras leyes conexas con ese tema, con el fin de que luego puedan instrumentarse mediante el diseño o refor- 
mulación de políticas públicas, planes nacionales y apropiaciones presupuestarias adecuadas para que pasen de lo meramente declarativo a lo pragmático. Ala par de ese tipo de leyes, deben formularse y reforzarse otras normativas, reglamentaciones y lineamientos administrativos que desarrollen y amplíen el reconocimiento y respeto alrededor de la diversidad, la educación bilingüe e intercultural, la perspectiva de género y la participación de todos los actores sociales vinculados con la política educativa, todo ello con una visión de integralidad que refuerce la promoción y protección de todos los derechos humanos en su esencia de indivisibilidad.

- Para los Estados que aún no han aprobado algunas leyes de esa naturaleza, que se avoquen a debatir ese tipo de iniciativas con amplia participación de la sociedad civil y las instituciones involucradas. En relación con las leyes ya aprobadas, revisar sus contenidos y obligaciones para aumentar el nivel de acciones proactivas en la promoción y protección de los derechos humanos mediante actividades de educación y capacitación integral, así como de la dotación de recursos necesarios para que esos procesos tengan continuidad y actualización constante.

- Reformular las políticas públicas, programas y planes con contenido en EDH para que haya mayor articulación entre sí y entre las distintas instituciones que las ejecutan para evitar duplicidad y mejorar la coordinación de actividades, productos y objetivos comunes. Fundamentalmente, deben mejorarse los contenidos de los programas especiales dentro de la educación formal e informal para perfilar una visión de EDH más integral e integradora. Es importante dar seguimiento y consolidación gradual de los consensos internacionales en la materia por medio de políticas públicas y otro tipo de directrices en atención a las obligaciones internacionales que tienen los Estados de adecuar su legislación interna mediante medidas administrativas o de otro carácter con esos propósitos.

- Fomentar campañas de concienciación y divulgación de los alcances conceptuales y contenidos de la EDH para reforzar los procesos culturales y educativos formales e informales para incidir en el reforzamiento y reformulación de patrones culturales. Estos propósitos pueden resultar enriquecidos si se juntan esfuerzos en el ámbito interamericano, promoviendo el intercambio de experiencias y la concertación de voluntades para pensar y llevar a cabo una estrategia regional, desarrollar las herramientas pedagógicas y delinear principios comunes para políticas de educación en los derechos humanos y la democracia.

\section{Conclusiones y recomendaciones del $I^{\circ}$ Informe Interamericano de la Educación en Derechos Humanos (2003)}

\section{Conclusiones}

En la primera parte de este Informe, referida a la adopción de normas y políticas públicas sobre EDH, se constató que entre 1990 y 2002 se habían dado importantes progresos en la ratificación de instrumentos internacionales relativos a este campo, que tales ratificaciones dieron pie a la inclusión o reforma de algunas normas constitucionales y que en un número creciente de países el propósito de establecer la educación 
en derechos humanos como un componente fundamental de la educación empezaba a permear los textos de las leyes generales de educación y en otros cuerpos de ley. Este fenómeno coincide, por supuesto, con los procesos de reforma educativa que se llevaron adelante desde la segunda mitad de la década de mil novecientos noventa y que en algunos países están entrando en vigencia ahora.

Del examen de los documentos que dan cuenta de las políticas educativas, el desarrollo institucional para el establecimiento de la EDH y la existencia de programas o proyectos para ponerla en marcha, se evidenció igualmente una evolución favorable en cuanto a la cantidad de esfuerzos realizados, principalmente en los últimos dos años del período analizado. Pero fueron notorios entonces una gran dispersión de tales esfuerzos, el hecho de que se trataba de eventos episódicos, como la operación de comisiones temporales de especialistas y la realización de experiencias piloto, la escasa participación de las organizaciones civiles, portadoras de una larga experiencia en la EDH y, la dependencia relativa de iniciativas y apoyos de la comunidad internacional más que de determinaciones de política nacional.

Quedó entonces pendiente indagar qué estaba ocurriendo con la incorporación de contenidos de derechos humanos y democracia en los instrumentos que se utilizan día a día para la organización de los procesos educativos: lineamientos curriculares, programas de asignaturas y textos.

Este segundo informe ha encontrado algunas novedades al respecto, que se subrayan a continuación.

\section{Valoración General:}

El resultado combinado de los estudios realizados en 2002 y 2003 sobre el estado que guarda la educación en derechos humanos en los países que han adherido al Protocolo de San Salvador puede considerarse alentador, en tanto muestra una tendencia positiva en el sentido de adoptar progresivamente medidas legales, institucionales y pedagógicas que doten a la educación de las calidades que pide el numeral segundo del artículo 13 del mencionado convenio. Sin embargo, el desarrollo es muy desigual para el conjunto de la región, no solamente en cuanto a la cantidad de contenidos incorporados, sino a su tratamiento. Preocupa un nivel relativamente alto de dispersión teórica en la definición de los contenidos y por tanto de las consecuencias metodológicas, y sobre todo pedagógicas, que de allí se pueden derivar.

\section{Sobre Reforma Legal y Reforma Curricular:}

Se constata que desde antes de 1990 algunos contenidos básicos ya estaban presentes en los instrumentos pedagógicos analizados, principalmente en los programas de estudio. Esto es particularmente interesante si se considera que las reformas constitucionales y legales que promueven tal incorporación son, en la mayor parte de los países, posteriores a esa fecha. El hecho pone en evidencia la existencia de un movimiento de reforma, favorable a la inclusión de estos contenidos, que probablemente viene desarrollándose 
desde los años de recuperación de la democracia en la región y que de alguna manera presionó sobre las reformas mismas.

En general los cambios identificados entre 1990 y 2003 -como se detalla más adelante- lo son principalmente de calidad y de extensión a lo largo del currículo y se evidencian más claramente en los textos escolares. Al contrario que en 1990, para $2003 \mathrm{el}$ desarrollo de algunos temas está ligeramente rezagado respecto del desarrollo normativo, si se tienen en cuenta los más recientes instrumentos y declaraciones internacionales - como la Carta Democrática Interamericana, la Convención contra la Corrupción o las recomendaciones de la Conferencia de Durban contra el racismo, la xenofobia y la discriminación; así como la legislación que desarrolla preceptos constitucionales novedosos, como la autonomía relativa de los pueblos indígenas en algunos países o la profundización de la descentralización, en otros.

Ciertos temas emergentes en el escenario de los derechos humanos y la democracia, como los problemas relacionados con la seguridad de las personas frente a la delincuencia organizada, el impacto de los procesos de liberalización del comercio, la reconfiguración de la correlación de fuerzas en el orden global o los problemas derivados de la criminalidad transnacional no han podido ser aun incorporados en los documentos y en los textos y no es posible saber si están siendo considerados en las aulas y de qué manera.

\section{Sobre Derechos Humanos y Garantías:}

A lo largo de la década creció la inclusión de referencias a los derechos humanos y a las garantías fundamentales en los documentos que orientan los currículos, en los programas de las asignaturas y en los textos escolares. Esta tendencia se caracteriza por varios rasgos: en todas las fuentes analizadas para el 2003 la incorporación es mucho más explícita que en 1990; se avanza del ámbito de los derechos civiles y políticos al de los derechos económicos, sociales y culturales y, en algunos países, se incorporan los derechos ambientales y otros de formulación más reciente; también se introduce una perspectiva de derechos sociales que balancea la tendencia a privilegiar un punto de vista de derechos individuales en 1990. En los programas de estudio de Colombia (2003) ocupan un lugar importante el conocimiento del Derecho Internacional Humanitario y de la Cruz Roja Internacional.

Ahora bien, tanto en 1990 como en 2003, el tratamiento de los derechos humanos y de las garantías fundamentales hace parte -por cierto en una proporción importantedel estudio de la constitución nacional, sus principios y contenidos. Esto incide en una limitación para mostrar con suficiente claridad la relación existente entre ese régimen de derechos y garantías constitucionales y el desarrollo de estándares de derechos humanos en la esfera internacional. Aparentemente esto le resta sentido al estudio de la Declaración Universal -incluido en la mayor parte de los programas; formaliza el estudio de los organismos internacionales en general- cuyo conocimiento se disocia del tema de los derechos; y debilita, cuando lo hay, el reconocimiento de los mecanismos internacionales de protección -que a su vez son presentados básicamente como instituciones. 


\section{Sobre el Estado, el Estado de Derecho y la Justicia:}

El estudio de la naturaleza, estructura y funcionamiento del Estado, de algunas instituciones públicas y del orden jurídico nacional, es considerado en los documentos, programas y/o los textos escolares de todos los países, tanto en 1990 como en 2003 . La inclusión de esta temática es sumamente desigual en cantidad y profundidad entre unos países y otros, pero en términos generales cubre un conjunto de asuntos que pueden considerarse útiles para inculcar el sentido de pertenencia a la nación y para orientar el desempeño de las ciudadanas y ciudadanos en la vida pública.

Entre 1990 y 2003 los programas y los textos ponen al día los cambios introducidos a lo largo de la década - principalmente mediante reformas constitucionales. En varios casos se aprecia un cambio de énfasis en favor de proveer a los educandos de una idea de equilibrio entre los poderes del Estado, de las funciones que le corresponden al Estado y al Gobierno en la promoción de un desarrollo social y económico equitativos, y de la importancia de la legalidad para una buena convivencia. En menos de la cuarta parte de los países se utiliza el concepto de Estado de Derecho para aludir estos equilibrios y esta legalidad y en un número semejante se introduce con un buen nivel de detalle la temática de la descentralización, los gobiernos locales y la participación directa de la ciudadanía en la gestión pública.

Las alusiones a la justicia son muy abundantes. Se la presenta como un valor, como un objetivo del Estado y de sus instituciones, y en menor medida como un medio de resolución de conflictos al que puedan apelar los ciudadanos. El estudio de los organismos judiciales y otros mecanismos hace parte del conocimiento de la estructura del Estado, pero no se advierte, en la documentación consultada, una intención de adiestramiento para el acceso a la justicia. Se han incorporado en cambio informaciones relevantes sobre defensor del pueblo, sobre algunos órganos de control y sobre dos recursos de protección clásicos: hábeas corpus y amparo constitucional.

Con excepción de un país, en el cual se menciona la corrupción administrativa, no se identificaron contenidos relacionados con la discusión de problemas que pudieran afectar la estabilidad y el buen desempeño de la estructura estatal y sus posibles soluciones.

\section{Sobre Democracia:}

La democracia como valor, como forma de gobierno y como atributo de las instituciones, las prácticas sociales y la vida personal es reiteradamente planteada en la documentación examinada para 1990 y para el 2003. Las modificaciones más importantes a lo largo de estos años tienen que ver con la concepción de la democracia como práctica y no únicamente como sistema; y con una creciente incorporación de la idea de participación ciudadana en la democracia, no confinada únicamente a los actos electorales y al ejercicio de los partidos políticos y de sus líderes.

Los organismos electorales son estudiados, en 1990 y 2003, como parte de la estructura del Estado. Se trata con poco detalle el tema de las elecciones nacionales, si bien en varios países se propone aprovechar la formación de asociaciones y gobiernos estudiantiles, como una oportunidad para inculcar el sentido de democracia y de sus prácticas. 
El tema de los partidos políticos nacionales, sus características, sus propuestas, su historia y su funcionamiento interno es tratado extensamente en un solo país. En otros se alude al régimen de partidos como un elemento constitutivo de la democracia, mientras el tratamiento de las tendencias políticas e ideológicas se coloca preferentemente en los programas y textos de historia y se trata de esa perspectiva.

No se han introducido todavía contenidos sobre gobernabilidad, transparencia o rendición de cuentas.

\section{Sobre Valores:}

La evolución de los documentos educativos en este aspecto, entre 1990 y 2003, se caracteriza por la incorporación progresiva de enunciados sobre valores, cada vez más diversos y más reiterativos. Se aprecia una tendencia de pasar de valores que inciden sobre conductas individuales a valores sociales y de convivencia democrática, de valores que se inducen a valores que se construyen y practican. Concomitantemente, mientras en 1990 la perspectiva dominante fue la de la moral y el civismo, para 2003 la perspectiva dominante es la de la ética y la democracia.

Cabe destacar la incorporación, cada vez con mayor importancia, a valores relativos a la convivencia entre las naciones y la solidaridad internacional. Sin embargo esto no aparece acompañado de una discusión de problemas relevantes en la esfera internacional, cuestión que quizá esté librada al trabajo en el aula - eso que llaman el curriculum oculto.

\section{Sobre Equidad de Género:}

Uno de los progresos más notables en prácticamente todos los países estudiados es la inclusión de la perspectiva de equidad de género. Al comparar en conjunto los documentos oficiales en materia educativa, los planes de estudio y los libros de texto en sus versiones de 1990 con las de 2003, se comprueba un significativo desarrollo, tanto cuantitativo como cualitativo. Desarrollo cuantitativo, porque aumentan los contenidos escolares específicos sobre el tema y aparecen en más grados escolares; desarrollo cualitativo, porque el tratamiento de estos contenidos se hace más extenso y profundo.

Si bien a la fecha encontramos disparidades en la amplitud y la forma en que el tema se trata en la educación sistemática de los distintos países, es importante destacar que, dentro de cada país, la década pasada condujo a una evolución muy positiva en el abordaje educativo de la igualdad de derechos entre hombres y mujeres.

\section{Sobre Diversidad Étnica:}

Otro desarrollo que se destaca durante la década pasada en los sistemas educativos de los países estudiados es un mayor reconocimiento y valorización de la diversidad racial o étnica de la población nacional y del continente en general. Del conjunto de datos de 2003 frente a los de 1990 observamos, como tendencias fuertes: (a) objetivos curriculares más explícitos, enfáticos y anti discriminatorios, (b) contenidos más extensos y que abordan problemas actuales, y (c) un buen número de iniciativas nacionales dirigidas a 
poblaciones específicas -en su mayor parte, indígenas- que procuran dar vigencia a su derecho a recibir una educación que respete su propia lengua y cultura. Son auń muy escasos los desarrollos relativos a las comunidades afrodescendientes.

\section{Sobre Sociedad Civil:}

A efectos de examinar si -y cómo- la participación de la sociedad civil es incorporada por los sistemas educativos de la región, utilizamos dos tipos de miradas complementarias. La primera se enfocó en un proceso real -los procedimientos para preparar e implementar currículo educativo en los países- y la otra, en las representaciones simbólicas que la educación transmite a niños, niñas y jóvenes como síntesis interpretativas de la realidad -los contenidos del currículo explícito y los textos de aula. Desde ambas perspectivas encontramos variaciones muy significativas durante la década pasada que indican un aumento de la presencia y valorización de múltiples actores civiles que interactúan con el Estado en la vida social.

\section{Recomendaciones}

- Alentar un esfuerzo conjunto de todos los países, incluyendo los Ministerios de Educación, las asociaciones de educadores y las organizaciones de la sociedad civil, para compartir y discutir el estado de incorporación de los derechos humanos en la educación, en procura de un estándar común, que aproveche los desarrollos exitosos y las lecciones aprendidas en la última década. Las Comisiones Nacionales de Educación en Derechos Humanos, que ya existen en varios países, pueden jugar un rol clave para llevar adelante este cometido.

- Movilizar el apoyo de la Corte, de la Comisión y del Instituto Interamericanos de Derechos Humanos para acompañar el esfuerzo de los países, sobre todo en la preparación de propuestas que promuevan entre los educandos, de una manera adecuada y práctica, los contenidos fundamentales de los instrumentos y los mecanismos interamericanos de defensa de los derechos humanos.

- Alentar a las redes de organismos electorales y de instituciones del Ombudsman, a participar activamente en la discusión y formulación de instrumentos pedagógicos comunes a la región, que mejoren el conocimiento y las prácticas sobre la democracia y sobre la defensa de los derechos humanos.

- Considerar mecanismos permanentes en los países - como las Comisiones de Educación en Derechos Humanos - que contribuyan a mantener al día los programas educativos y a producir materiales pedagógicos que respondan a los nuevos desafíos y a los problemas emergentes de los derechos humanos y la democracia, en un mundo cada vez más integrado por los medios electrónicos de intercomunicación e información.

- Atender, de modo sistemático, la incorporación de contenidos y metodológicas de enseñanza de derechos humanos en los procesos de formación de los profesionales que tienen a cargo las labores docentes, incluyendo los institutos normales superiores y las universidades. 


\section{Notas}

1. En algunas secciones, este trabajo retoma y reelabora textos de los informes preparados por el IIDH e ideas originalmente planteadas en un artículo de Roberto Cuéllar (Director Ejecutivo del IIDH) para el libro homenaje a Antonio A. Cançado Trindade, por aparecer.

2. Coordinadores de la Unidad de Investigaciones y la Unidad Pedagógica del Instituto Interamericano de Derechos Humanos, respectivamente.

3. Los resultados pueden ser consultados en la sección Mapas de Progreso en Derechos Humanos, en la página electrónica del IIDH: www.iidh.ed.cr.

4. Los informes se encuentran en Secciones especializadas/Educación en derechos humanos, de la página electrónica del IIDH ya indicada.

5. Ver a propósito de estas consideraciones el texto institucional: El Panorama de los Derechos Humanos y la Democracia en América Latina, IIDH, San José, 2003. Disponible en el sitio web del IIDH: http://www.iidh.ed.cr/Documentos/Visión IIDH2003.pdf

6. Para una exposición más extensa, ver: Marco para el desarrollo de una estrategia Institucional, Documento de trabajo, IIDH, San José, 2003.

7. Como se indicó antes, estos campos temáticos son: acceso a la justicia, participación política y educación en derechos humanos, entendidos ellos mismos como espacios de interacción entre derechos, situaciones político-institucionales y procesos sociales relevantes.

8. Equidad de género; reconocimiento de la diversidad étnica e interacción de la sociedad civil con el Estado. 
60 Encounters/Encuentros/Rencontres 